\title{
Guidelines for screening and monitoring of cardiometabolic risk in schizophrenia: systematic evaluation
}

M. De Hert, D. Vancampfort, C. U. Correll, V. Mercken, J. Peuskens, K. Sweers,

R. van Winkel and A. J. Mitchell

\section{Background}

Metabolic and cardiovascular health problems have become a major focus for clinical care and research in schizophrenia.

\section{Aims}

To evaluate the content and quality of screening guidelines for cardiovascular risk in schizophrenia.

\section{Method}

Systematic review and quality assessment of guidelines/ recommendations for cardiovascular risk in people with schizophrenia published between 2000 and 2010, using the Appraisal of Guidelines for Research and Evaluation (AGREE)

\section{Results}

The AGREE domain scores varied between the 18 identified guidelines. Most guidelines scored best on the domains 'scope and purpose' and 'clarity of presentation'. The domain 'rigour of development' was problematic in most guidelines, and the domains 'stakeholder involvement' and 'editorial independence' scored the lowest. The following

measurements were recommended (in order of frequency): fasting glucose, body mass index, fasting triglycerides, fasting cholesterol, waist, high-density lipoprotein/low-density lipoprotein, blood pressure and symptoms of diabetes. In terms of interventions, most guidelines recommended advice on physical activity, diet, psychoeducation of the patient, treatment of lipid abnormalities, treatment of diabetes, referral for advice and treatment, psychoeducation of the family and smoking cessation advice. Compared across all domains and content, four European guidelines could be recommended.

\section{Conclusions}

Four of the evaluated guidelines are of good quality and should guide clinicians' screening and monitoring practices. Future guideline development could be improved by increasing its rigour and assuring user and patient involvement.

\section{Declaration of interest}

M.D.H. has been a consultant for, received grant/research support and honoraria from, and been on the speakers/ advisory boards of Astrazeneca, Bristol-Myers Squibb, Eli Lilly, Janssen-Cilag, Lundbeck JA, Pfizer and Sanofi Aventis. $\mathrm{He}$ is co-author of two of the assessed guidelines.

C.C. has been a consultant to, or has received honoraria from, AstraZeneca, Bristol-Myers Squibb, Cephalon,

Eli Lilly, Medicure, OrthoMcNeill-Janssen, Otsuka, Pfizer, Schering-Plough, Supernus, and Vanda, and has served on the speaker's bureau of AstraZeneca, Bristol-Myers Squibb/Otsuka and Pfizer. J.P. has been a consultant for and co-operated in clinical trials with AstraZeneca, BristolMyers Squibb, Eli Lilly, Janssen-Cilag, Lundbeck, Pfizer, Sanofi Aventis. He has also received research grants from AstraZeneca, Janssen-Cilag, Eli Lilly, Lundbeck and Sanofi-Aventis. R.V.W. has been a consultant for Eli Lilly and received honoraria from AstraZeneca, Eli Lilly and Janssen-Cilag.
In recent years, physical health issues and specifically metabolic and cardiovascular comorbidity in different severe mental illnesses have become a major focus in both clinical care and research. ${ }^{1-10}$ The association of schizophrenia with metabolic and other cardiovascular disease risk factors is a complex interplay between environmental (lifestyle, diet, substance use), genetic and illnessrelated factors, such as specific symptoms, as well as effects of treatment. Both older and more recent studies have confirmed the high rate of premature mortality in people with schizophrenia due to cardiovascular disease. ${ }^{11-20}$

The need for screening, monitoring and prevention of diabetes and other cardiovascular disease risk factors has been acknowledged in the psychiatric literature and in some of the more recent general treatment guidelines. ${ }^{21-25}$ However, the evaluation of screening practices by clinicians has consistently shown that they are suboptimal. ${ }^{26-37}$ Different national and international groups have developed guidelines relating to the monitoring and management of the increased risk for physical comorbidity in people with schizophrenia. A review in 2006 indicated substantial differences between six guidelines. ${ }^{37}$

Guidelines on the same topic, in different domains in medicine, can differ or be in conflict with other recommendations in the same domain. ${ }^{38}$ Not all guidelines have been developed with the same amount of rigour and authors' independence. Clinicians should be able to identify and have access to guidelines, which are based on the best evidence. For the individual clinician as well as services it can be difficult to identify and select a specific recommendation to use in daily practice.

The aim of this study was to perform a systematic review of the available clinical practice guidelines for the screening and monitoring of cardiometabolic risk in people with schizophrenia and related psychotic disorders. The quality of these guidelines is assessed with the Appraisal of Guidelines for Research and Evaluation (AGREE). ${ }^{39-40}$

\section{Method}

Clinical practice guidelines for the screening and monitoring of people with schizophrenia were identified by a systematic search using PubMed, CINAHL and Embase (from 1 January 2000 until 1 April 2010) and the following search terms: Schizophrenia, Psychotic disorder, Psychosis, Mental illness, Diabetes, Cardiovascular diseases, Metabolic syndrome, Safety management and prevention, Guideline(s), Consensus development, Practice guideline(s). In the retrieved papers related articles were identified in reference lists. 
Exclusion criteria were: papers only evaluating or comparing the effects of specific antipsychotic agents; general treatment guidelines for schizophrenia or psychotic disorders; guidelines specific for diabetes or cardiovascular diseases; guidelines only for children, adolescents or elderly people. All European languages were allowed if the papers met all of the following inclusion criteria: schizophrenia, cardiometabolic risk, adults and guidelines.

The evaluation and comparison of the guidelines was performed according to AGREE (2003), which is designed as a framework for the assessment of the quality of guidelines for clinical practice (www.agreecollaboration.org). ${ }^{39-40}$

The instrument consists of 23 items grouped in six domains: scope and purpose; rigour of development; stakeholder involvement; clarity and presentation; applicability; and editorial independence. Each item is scored on a 4-point scale (strongly agree, agree, disagree and strongly disagree) with proposed anchor points to evaluate in which way the guideline fulfils the domain. The scores are standardised in a percentage score that enables comparison between guidelines (obtained score-minimum possible score)/(maximum possible score-minimum possible score). The final component of the AGREE instrument involves a recommendation regarding the use of the guidelines in practice as 'recommended', 'recommended (with provisos or exceptions)', 'would not recommend or unsure', depending on the number of items and domains if the score was $>60 \%, 30-60 \%$ and $<30 \%$, respectively. Three raters (D.V., K.S. and M.D.H.) independently scored the identified guidelines (M.D.H. acknowledges a potential conflict of interest because he co-authored two of the assessed guidelines). A mean score was calculated for each item from which the percentage score was derived according to the AGREE manual. In addition, each guideline was independently evaluated regarding the specific content and scope of what should be monitored by whom. Process indicators were predefined and scored on a standardised scoring sheet (online supplement 1). Intraclass correlation coefficients (ICC) with a $95 \%$ confidence interval were calculated as an overall indicator of agreement among the raters for each of the 23 items of the AGREE instrument. ${ }^{41}$

\section{Results}

The initial search with all search terms yielded 4608 hits (Fig. 1). That number was reduced to 18 when the specific inclusion criteria were applied. A total of 54 guidelines were found of which 35 were excluded: 23 duplicate papers (either by the same or different authors with similar guideline content in different journals); ${ }^{37,42-63}$ 4 general schizophrenia treatment guidelines; ${ }^{23,24,64,65} 3$ guidelines only for children or adolescents; ${ }^{66-68} 2$ for people with bipolar disorder; $;^{69-70}$ and 3 diabetes guidelines. ${ }^{71-73}$ One guideline for metabolic screening in people with schizophrenia was excluded because it was only available in Japanese and we were not able to get it translated. ${ }^{74}$

A total of 18 unique guidelines were identified for AGREE evaluation either from the USA (2), Australia (2), Brazil (1), Canada (1) or Europe (12), and all were published between 2004 and 2010 (online Table DS1). ${ }^{75-92}$ All papers covered diabetes and cardiovascular disease risk in individuals treated with antipsychotic agents, whereas some had a broader scope also including other physical health domains and other side-effects. ${ }^{78,85,86,89,91}$

\section{Interrater reliability}

The overall ICC value among the observers was 0.89 (95\% CI $0.88-0.91, P<0.0001)$. None of the scores on individual items for all assessed guidelines differed more than one point on the AGREE scale.

\section{Evaluation of the quality of the guidelines}

There was wide variation in standardised scores of the different domains (online Table DS1). Apart from stakeholder involvement, all of the domains had a difference of at least $45 \%$ between the highest and lowest scoring guideline. Only two domains had a mean score above 50\% (scope and purpose, clarity and presentation).

The highest mean domain score, derived from pooled scores, was for scope and purpose (56.4\%) with five guidelines scoring below $40 \%$ and six having a score of $70 \%$ or above. The highest score, $81.5 \%$, was achieved by three guidelines. ${ }^{75,77,79}$

Clarity and presentation was satisfactory in most guidelines (50.6\%), only four had a score of $31 \%$ or lower. All the guidelines with a score above $50 \%$ presented a clear table or figure, summarising the proposed screening content and time intervals.

Regarding the domain rigour of development all except one guideline had a score below $50 \%{ }^{89}$ Although some guidelines presented data from a systematic review of the literature, the search strategy for literature selection was missing in all but one guideline. ${ }^{89}$ Only two guidelines presented levels/quality of the evidence $^{84,86}$ and one presented meta-analytic data. ${ }^{89}$ More than half $(61 \%)$ of the guidelines were developed with a consensus model (online Table DS2). Within this domain the criterion about the updating of the recommendation was not fulfilled by any of the guidelines. The older UK guideline has a low score on this item, but the paper was published in a themed issue of the journal, with different papers presenting a systematic review of the literature in that same issue. ${ }^{81}$

Scores in the application domain were satisfactory in five guidelines. The guidelines with a low score on this domain failed to discuss the organisational aspects of introducing screening and monitoring. Health economic aspects were mentioned in some guidelines but the additional cost of screening and monitoring was explicitly available in only one. ${ }^{91}$

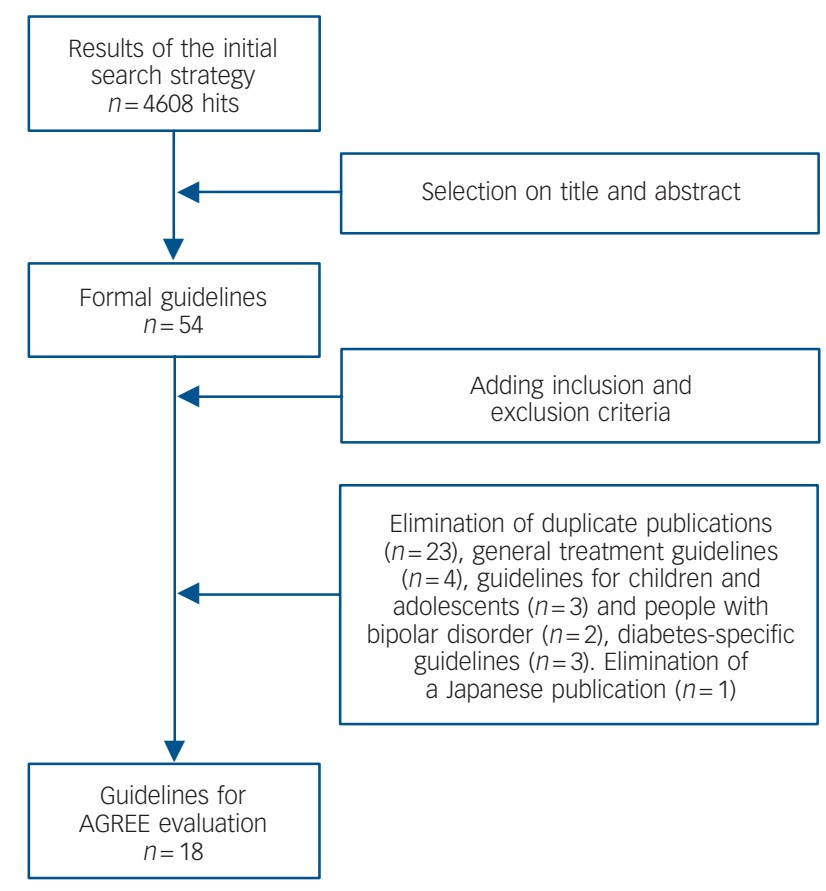

Fig. 1 Results of the systematic literature search. 
Editorial independence was the only domain with a range of scores from 0 to $100 \%$. Eight guidelines had industry involvement and in only seven there was a declaration of conflicts of interest. Some publications were not industry sponsored but lacked a conflict of interest section resulting in a low AGREE score on this item (online Table DS2).

The lowest mean domain score was for stakeholder involvement $(30.6 \%)$, with only six guidelines scoring above $30 \%$. Only in two guidelines had patients been involved in the guidelines' development. The proposed guidelines were never tested on the intended users. Except for three, ${ }^{76,85,92}$ all the guidelines were developed by a multidisciplinary group. Official medical societies were involved in the oldest ${ }^{75}$ and in six of the seven most recent guidelines (online Table DS2). ${ }^{78,79,82,83,89,90}$

Comparing the guidelines across the overall scores in the different domains, four European ${ }^{77,79,83,89}$ and one US ${ }^{86}$ guideline could be recommended, whereas four guidelines failed in nearly all domains. ${ }^{76,85,87,92}$

\section{Guideline development process}

Online Table DS2 presents details about the guideline development process. Most were based on a selective or systematic literature review. A majority was based on a consensus model involving different medical disciplines. People with schizophrenia were the target for the proposed recommendations in all guidelines, although some broadened the scope to people with other severe mental illnesses being treated with antipsychotic medication. Four guidelines specifically mentioned paediatric patients as a vulnerable group. ${ }^{75,78,79,83}$

\section{Recommended assessment of risk factors for diabetes and cardiovascular disease}

All but one ${ }^{90}$ guideline recommended assessment of family history, and three ${ }^{85,87,90}$ failed to include personal history (online Table DS3). Only $56 \%$ of the guidelines proposed a general physical examination of the patient. Assessment of other known risk factors for diabetes and cardiovascular disease was incomplete in most of the guidelines; $44 \%$ even failed to mention smoking. Three included a comprehensive risk assessment. ${ }^{79,80,91}$

Most of the guidelines stated that the frequency of monitoring is dependent on the presence of risk factors (including being overweight and obesity) and on the time since starting the antipsychotic medication (more frequent monitoring when close to starting medication) (online Table DS4). A minority of guidelines $(28 \%)$ suggested that the frequency of monitoring is dependent on specific antipsychotic agents. In most cases, they stipulated that it is the responsibility of the psychiatrist/prescriber to ensure that the screening and monitoring is being conducted. Six guidelines explicitly also involved a general practitioner (GP) in this responsibility and promoted models of shared care. ${ }^{79-81,83-91}$

\section{Comparison of recommendations in the guideline}

Overall, the recommendations across guidelines were more similar than dissimilar regarding variables that should be assessed both at baseline and over time (online Table DS5). Apart from weight and body mass index, which were present in most guidelines (89\%), a majority of guidelines also included measurements of waist circumference $(83 \%)$. All guidelines also included the assessment of fasting glucose (online Table DS5), and the majority (89\%) also included the assessment of fasting lipids (online Table DS5). The major differences between guidelines were in the timing and the interval between assessments. The more recent guidelines were more detailed and included additional evaluations about personal and family history and cardiovascular risk factors. Six guidelines (33\%) failed to mention blood pressure monitoring. A substantial number of them also failed to mention specific timing for screening or to mention cut-off or target values for the assessed variables (most frequently for the lipid measurements). For glucose values the reference values presented were either based on the American Diabetes Association or World Health Organization thresholds at the time of publication. For lipid values, the cut-offs of the Adult Treatment Panel were used most frequently. In $60 \%$ of the guidelines, the reference values were based on the recommendations of official societies (either cardiology or diabetology).

For glucose abnormalities, four guidelines mentioned the possibility of assessing non-fasting glucose (although they, at the same time, recommended assessing fasting lipid profile) and only two recommended glycosylated haemoglobin (HbAlc). Oral glucose tolerance tests were recommended in six; in case of impaired fasting glucose values. ${ }^{77,80,82-84,88}$ Monitoring for signs and symptoms of diabetes was recommended by different guidelines $(67 \%)$, whereas only a few $(33 \%)$ explicitly mentioned assessing diabetic ketoacidosis (online Table DS6). The concept of the metabolic syndrome was formally included in only four.

Guidelines with a more global physical health scope recommended additional laboratory testing, ranging from prolactin levels to viral serology and different additional somatic investigations (online Table DS6). In total, 50\% proposed ECG monitoring, at least when using drugs with a potential for QTc prolongation.

Therapeutic recommendations varied substantially across the different domains assessed (online Table DS7). Most guidelines recommended education of patients (83\%), although only $50 \%$ involved the family (online Table DS7). A small majority (56\%) recommended switching of antipsychotic agents in the case of significant increases in risk factors. A minority $(33 \%)$ considered the initial choice of a specific antipsychotic to be important. Advice on diet and exercise was present in most guidelines, but recommendations were rarely specific enough to guide clinical practice. Only 50\% of them recommended promoting smoking cessation.

In most of the guidelines, treatment for diabetes and lipid abnormalities was addressed, recommending that individuals with significant abnormalities be referred to a GP or a medical specialist for evaluation and/or treatment. Only six (33\%) considered treatment for hypertension. Educational interventions for mental health workers, GPs or medical specialists were rarely proposed (online Table DS7).

\section{Discussion}

This is the first study that systematically evaluates the content and quality of practice guidelines for the screening and monitoring of diabetes and cardiovascular risk in people with schizophrenia. For the qualitative and quantitative assessment of these guidelines, we used AGREE, a widely used and accepted tool for the quality assessment of such material. ${ }^{39,40}$ The assessed guidelines differed significantly regarding the different AGREE domains. The highest scores were obtained for scope and purpose and clarity of presentation. The lowest scores were found for the domains stakeholder involvement and rigour of development. There was less difference between the basic sets of variables that should be assessed in patients, but substantial differences were apparent in the level of detail and timing of the recommended monitoring and proposed therapeutic strategies.

\section{Clinical recommendations}

After a baseline assessment, 10 of the 18 guidelines recommended monitoring after the first 3-4 months of treatment, but 4 
recommended monitoring after 4-6 weeks and 1 required only monitoring at 6 months. The following measurements were recommended, in order of frequency: fasting glucose, body mass index, fasting triglycerides, fasting cholesterol, waist, high density lipoprotein/low density lipoprotein, blood pressure and symptoms of diabetes. In terms of interventions, most guidelines recommended advice on physical activity, advice on diet, psychoeducation of the patient, treatment of lipid abnormalities, treatment of diabetes, referral for advice and treatment, psychoeducation of the family and smoking cessation advice. Of the screening tests, fasting glucose, fasting triglycerides and fasting cholesterol may be less easily integrated into routine care because of the need to organise fasting blood tests. Thus compliance with such tests is often less than $20 \%{ }^{28,29,31}$ Alternatives such as nonfasting $\mathrm{HbAlc}$ are promising but require further validation in psychiatric settings. ${ }^{93-95}$

\section{Implementation of guidelines}

Clinical practice guidelines are considered a good option for translating research into clinical practice. They are defined as 'systematically developed statements to assist practitioner and patient decisions about appropriate healthcare for specific clinical circumstances. ${ }^{96}$ Their potential to improve patient care and outcomes depends largely on the quality and independence of the guideline. ${ }^{97}$ Recommendations may be biased because of non-systematic selection, inadequate interpretation or lack of scientific evidence. The content may initially be decided through consensus, whereas scientific evidence to support the consensus is added afterwards. The influence of the context within which the guidelines are produced (for example by medical societies or with support of pharmaceutical companies) has also been mentioned in relation to the variation across guidelines. ${ }^{97-99}$

Quality evaluations have recently been performed for other diseases in relation to metabolic and cardiovascular risk monitoring. ${ }^{100-102}$ Similar to our findings, for diabetes and cardiovascular disease the rigour of development and other quality indications, such as stakeholder involvement and editorial independence, were not ideal in a number of these guidelines. This was the case, despite medical societies developing stringent methodologies for these diseases according to internal guidelines/ procedures. ${ }^{103}$ Moreover, editorial independence was also often a problematic area, and frequently guidelines were not based on high-quality evidence. ${ }^{38,98-104}$

\section{Limitations}

A limitation of the AGREE methodology is the degree of subjective judgement. ${ }^{100,101}$ This can be partly overcome through the evaluation by different independent reviewers, as was done in this study, and with high interrater reliability. We did not contact the original authors for additional information. This could have been relevant for those guidelines not having industry sponsoring, but failing to report conflicts of interest (in the appraisal, such guidelines received a score of 'totally disagree' on item 22). Furthermore, the AGREE evaluation does not evaluate the impact of the guidelines on patient outcome. ${ }^{100}$

Authors of a recent joint paper on the Schizophrenia Patient Outcomes Research Team (PORT) guidelines acknowledged the difficulty of getting published guidelines to change clinical practice. ${ }^{105}$ This is supported by a number of studies. So far all studies that assessed the impact of the American Diabetes Association/American Psychiatric Association (ADA/APA) 2004 guidelines ${ }^{75}$ in the USA, which went hand in hand with extensive educational efforts, suggest that the impact on real-life screening and monitoring rates of people receiving antipsychotics in different population samples in the USA is minimal to poor. ${ }^{28-34}$ Similar results have also emerged in the UK. ${ }^{27}$ Of note, although often calling for research, none of the guidelines explicitly mentioned an update procedure. The only guideline that has undergone an extensive review and update process is the ADA/ APA consensus document. ${ }^{75} \mathrm{~A}$ new version of this guideline is currently being finalised.

\section{General conclusions}

Overall, we conclude that several adequate guidelines for screening and monitoring are available. The published guidelines all focus on the same evidence base but differ mainly regarding the timing of monitoring and the scope of physical health domains that are to be monitored. Comparing the guidelines across the overall scores in the different domains of the AGREE assessment and taking into account the level of detail and comprehensiveness of the monitoring, four European guidelines can be recommended for clinical use in daily practice. ${ }^{77,79,83,89}$ However, none of the guidelines had a proposed schedule for an update and they all require more rigorous implementation strategies, together with studies into the impact on actual screening rates; long-term patient outcomes should also be put in place.

Based on this review of the guidelines, a monitoring protocol for managing cardiovascular disease risk in patients in clinical practice is proposed in Fig. 2. All individuals with schizophrenia should be under active care (regardless of treatment condition) and be screened at least annually if they have normal baseline values. Those who already present with cardiovascular risk factors should be monitored more frequently. At the start of a new treatment, assessments should be repeated 6 and 12 weeks after initiation of the new antipsychotic drug treatment (the 6-week assessment has only been endorsed in some European guidelines and the advantages of this additional, early assessment time point still have to be demonstrated). These recommendations are in general agreement with the National Institute for Health and

\begin{tabular}{|c|c|c|c|c|}
\hline & Baseline & 6 weeks (if starting drug treatment) & 12 weeks (if starting drug treatment) & At least annually thereafter \\
\hline Medical history & $\checkmark$ & & & \\
\hline Weight/waist/BMl & $\checkmark$ & $\checkmark$ & $\checkmark$ & $\checkmark$ \\
\hline Blood pressure & $\checkmark$ & $\checkmark$ & $\checkmark$ & $\checkmark$ \\
\hline Fasting glucose & $\checkmark$ & $\checkmark$ & $\checkmark$ & $\checkmark$ \\
\hline Fasting lipids & $\checkmark$ & $\checkmark$ & $\checkmark$ & $\checkmark$ \\
\hline Lifestyle advice & $\checkmark$ & $\checkmark$ & $\checkmark$ & $\checkmark$ \\
\hline
\end{tabular}

Fig. 2 Monitoring protocol for managing individuals with normal baseline values at start of an episode of care.

The 6-week assessment has only been endorsed in some European guidelines and the advantages of this additional, early assessment time point still have to be demonstrated. Body mass index (BMI): during initial phases of treatment, it is important to measure weight weekly to identify individuals who may be gaining weight rapidly. 
Clinical Excellence guidelines ${ }^{24}$ which stress the need to prevent cardiovascular disease and to undertake metabolic risk assessment, but do not provide clear guidance on which evaluations need to be done when, and with the Canadian Diabetes Association clinical practice guidelines, which considers schizophrenia as a risk factor for diabetes. ${ }^{71}$ Based on a systematic review of the metabolic effects of antipsychotics in children and adolescents, similar guidelines for cardiometabolic screening have been proposed recently. ${ }^{106}$ Based on recent data in drug-naive individuals ${ }^{107-109}$ and recent general treatment guidelines, ${ }^{21,23,106}$ antipsychotic medications with a high liability to induce metabolic changes are not recommended to be used as first-line agents in first-episode/never exposed individuals.

As in other healthcare domains, improvement is needed in the quality of the guidelines for screening and monitoring cardiometabolic risks in people with schizophrenia. In order for this shift to happen, guidelines should adhere more closely to the methodology proposed in the AGREE instrument. Finally, due to the increasing burden of obesity among individuals with schizophrenia and the potential for long-term cardiometabolic comorbidities, clinicians need to have access to key recommendations from the best available guidelines, be critical of how these are developed and consider their appropriateness for use in their own clinical practice.

M. De Hert, MD, PhD, University Psychiatric Centre, KU Leuven campus Kortenberg Leuvensesteenweg, Kortenberg, Belgium; D. Vancampfort, PT, MSc, University Psychiatric Centre, KU Leuven campus Kortenberg, Leuvensesteenweg, Kortenberg and Department of Rehabilitation Sciences, Faculty of Kinesiology and Rehabilitation Sciences, Catholic University Leuven, Heverlee, Belgium; C. U. Correll, The Zucker Hillside Hospital, Glen Oaks, and Albert Einstein College of Medicine, Bronx, New York, USA; V. Mercken, RN, J. Peuskens, MD, PhD, K. Sweers, RN, University Psychiatric Centre, KUL campus Kortenberg, Leuvensesteenweg, Kortenberg, Belgium; R. van Winkel, MD, PhD, University Psychiatric Centre, KU Leuven campus Kortenberg, Leuvensesteenweg, Kortenberg, Belgium, and Department of Psychiatry and Neuropsychology, EURON, South Limburg Mental Health Research and Teaching Network, Maastricht University Medical Centre, Maastricht, The Netherlands;

A. J. Mitchell, MRCPsych, Leicester General Hospital, Leicester Partnership Trust, A. J. Mitchell, MRCPSych, Leicester General Hospital, Leicester Partnership Trust,
and Department of Cancer \& Molecular Medicine, Leicester Royal Infirmary, University of Leicester, UK

Correspondence: Marc De Hert, University Psychiatric Centre, KU Leuven, campus Kortenberg Leuvensesteenweg 517, 3070 Kortenberg, Belgium. Email: marc.de.hert@uc-kortenberg.be

First received 12 Jul 2010, final revision 7 Nov 2010, accepted 17 Jan 2011

\section{References}

1 Bresee LC, Majumdar SR, Patten SB, Johnson JA. Prevalence of cardiovascular risk factors and disease in people with schizophrenia: a population-based study. Schizophr Res 2010; 117: 75-82.

2 Fleischhacker WW, Cetkovich-Bakmas $\mathrm{M}$, De Hert $\mathrm{M}$, Hennekens $\mathrm{CH}$ Lambert $\mathrm{M}$, Leucht $\mathrm{S}$, et al. Cormorbid somatic illnesses in patients with severe mental disorders: clinical, policy and research challenges. J Clin Psychiatry 2008; 69: 514-9.

3 Goff DC, Cather C, Evins AE, Henderson DC, Freudenreich O, Copeland PM, et al. Medical morbidity and mortality in schizophrenia: guidelines for psychiatrists. J Clin Psychiatry 2005; 66: 183-94.

4 Leucht S, Burkard T, Henderson J, Maj M, Sartorius N. Physical illness and schizophrenia: a review of the literature. Acta Psychiatr Scand 2007; 116: 317-33.

5 Mcintyre RS, Leiter L, Yale J-F, Lau D, Stip E, Ur E, et al. Schizophrenia, glycemia and antipsychotic medications: an expert consensus review. Can J Diabetes 2005; 29: 113-21.

6 Mitchell AJ, Malone D. Physical health and schizophrenia. Curr Opin Psychiatry 2006; 19: 432-7.

7 Newcomer JW. Second-generation (atypical) antipsychotics and metabolic effects: a comprehensive literature review. CNS Drugs 2005; 19: 1-93.

8 Newcomer JW. Antipsychotic medications: metabolic and cardiovascular risk. J Clin Psychiatr 2007; 68 (suppl 4): 8-13.
9 Smith M, Hopkins D, Peveler RC, Holt RIG, Woodward M, Ismail K. First- $v$. second-generation antipsychotics and risk for diabetes in schizophrenia: systematic review and meta-analysis. Br J Psychiatry 2008; 192: 406-11.

10 Stahl SM, Mignon L, Meyer JM. Which comes first: atypical antipsychotic treatment or cardiometabolic risk? Acta Psychiatr Scand 2009; 119: 171-9.

11 Capasso RM, Lineberry TW, Bostwick JM, Decker PA, St Sauver J. Mortality in schizophrenia and schizoaffective disorder: an Olmsted County, Minnesota cohort: 1950-2005. Schizophr Res 2008; 98: 287-94.

12 Colton CW, Manderscheid RW. Congruencies in increased mortality rates, years of potential life lost, and causes of death among public mental health clients in eight states. Prev Chronic Dis 2006; 3: A42.

13 De Hert M, Correll CU, Cohen D. Do antipsychotic medications reduce or increase mortality in schizophrenia? A critical appraisal of the FIN-11 study. Schizophr Res 2010; 117: 68-74.

14 Laursen TM, Munk-Olsen T, Nordentoft M, Mortensen PB. Increased mortality among patients admitted with major psychiatric disorders: a register-based study comparing mortality in unipolar depressive disorder, bipolar affective disorder, schizoaffective disorder, and schizophrenia. J Clin Psychiatry 2007; 68: 899-907.

15 Osborn DP, Levy G, Nazareth I, Petersen I, Islam A, King MB. Relative risk of cardiovascular and cancer mortality in people with severe mental illness from the United Kingdom's general practice research database. Arch Gen Psychiatry 2007; 64: 242-9.

16 Ösby U, Correia N, Brandt L, Ekbom A, Sparen P. Mortality and causes of death in schizophrenia in Stockholm county, Sweden. Schizophr Res 2000; 45: 21-8.

17 Ösby $\mathrm{U}$, Correia N, Brandt L, Ekbom A, Sparen P. Time trends in schizophrenia mortality in Stockholm County, Sweden: cohort study. BMJ 2000; 321: 483-4.

18 Saha S, Chant D, McGrath J. A systematic review of mortality in schizophrenia: is the differential mortality gap worsening over time? Arch Gen Psychiatry 2007; 64: 1123-31.

19 Tiihonen J, Lönnqvist J, Wahlbeck K, Klaukka T, Niskanen L, Tanskanen A, et al. 11-year follow-up of mortality in patients with schizophrenia: a population-based cohort study (FIN11 study). Lancet 2009; 374: 620-7.

20 Weinmann S, Read J, Aderhold V. Influence of antipsychotics on mortality in schizophrenia: systematic review. Schizoph Res 2009; 113: 1-11.

21 Buchanan RW, Kreyenbuhl J, Kelly DL, Noel JM, Boggs DL, Fischer BA, et al. Schizophrenia Patient Outcomes Research Team (PORT). The 2009 schizophrenia PORT psychopharmacological treatment recommendations and summary statements. Schizophr Bull 2010; 36: 71-93.

22 Citrome L, Yeomans D. Do guidelines for severe mental illness promote physical health and well-being? J Psychopharmacol 2005; 19: 102-9.

23 Kreyenbuhl J, Buchanan RW, Dickerson FB, Dixon LB. The schizophrenia patient outcomes research team (PORT): updated treatment recommendations 2009. Schizophr Bull 2010; 36: 94-103.

24 National Institute for Health and Clinical Excellence. Core Interventions in the Treatment and Management of Schizophrenia in Adults in Primary and Secondary Care. NICE, 2009 (http://guidance.nice.org.uk/CG82/Guidance).

25 Tandon R, Keshavan MS, Nasrallah HA. Schizophrenia, "just the facts" 5 . Treatment and prevention. Past, present, and future. Schiophr Res 2010; 122; $1-23$.

26 Allochis G, Cavallaro R, Milano W, Monteleone P, Paroli A, Rossi A, et al. Problematiche nel monitoraggio e nella gestione della salute fisica del paziente con schizofrenia [in Italian]. G Ital Psicopathol 2007; 13: 528-40.

27 Barnes TR, Paton C, Cavanagh MR, Hancock E, Taylor DM; UK Prescribing Observatory for Mental Health. A UK audit of screening for the metabolic side effects of antipsychotics in community patients. Schizophr Bull 2007; 33 1397-403.

28 Buckley PF, Miller DD, Singer B. Clinicians' recognition of the metabolic adverse effects of antipsychotic medications. Schizophr Res 2005; 79: 281-8.

29 Haupt DW, Rosenblatt LC, Kim E, Baker RA, Whitehead R, Newcomer JW. Prevalence and predictors of lipid and glucose monitoring in commercially insured patients treated with second-generation antipsychotic agents. Am J Psychiatry 2009; 166: 345-53.

30 Hsu C, Ried LD, Bengtson MA, Garman PM, McConkey JR, Rahnavard F. Metabolic monitoring in veterans with schizophrenia-related disorders and treated with second-generation antipsychotics: findings from a Veterans Affairs-based population. J Am Pharm Assoc 2008; 48: 393-400.

31 Morrato EH, Newcomer JW, Allen RR, Valuck R. Prevalence of baseline serum glucose and lipid testing in users of second-generation antipsychotic drugs: a retrospective, population-based study of Medicaid claims data. J Clin Psychiatry 2008; 69: 316-22. 
32 Morrato EH, Newcomer JW, Kamat S, Baser O, Harnett J, Cuffel B. Metabolic screening after the American Diabetes Association's consensus statement on antipsychotic drugs and diabetes. Diabetes Care 2009; 32: 1037-42.

33 Morrato, EH, Druss B, Hartung DM, Valuck RJ, Allen R, Campagna E, et al. Metabolic testing rates in 3 state Medicaid programs after FDA warnings and ADA/APA recommendations for second-generation antipsychotic drugs. Arch Gen Psychiatry 2010; 67: 17-24.

34 Morrato EH, Nicol GE, Maahs D, Druss BG, Hartung DM, Valuck RJ, et al. Metabolic screening in children receiving antipsychotic drug treatment. Arch Pediatr Adolesc Med 2010; 164: 344-51.

35 Nasrallah HA, Meyer JM, Goff DC, McEvoy JP, Davis SM, Stroup TS, et al. Low rates of treatment for hypertension, dyslipidemia and diabetes in schizophrenia: data from the CATIE schizophrenia trial sample at baseline. Schizophr Res 2006; 86: 15-22.

36 Newcomer JW, Nasrallah HA, Loebel AD. The atypical antipsychotic therapy and metabolic issues national survey. J Clin Psychopharmacol 2004; 24: 1-6.

37 Cohn TA, Sernyak MJ. Metabolic monitoring for patients treated with antipsychotic medications. Can J Psychiatry 2006; 51: 492-501.

38 Ferket BS, Colkesen EB, Visser JJ, Spronk S, Kraaijenhagen RA, Steyerberg EW, et al. Systematic review of guidelines on cardiovascular risk assessment: which recommendations should clinicians follow for a cardiovascular health check? Arch Intern Med 2010; 170: 27-40.

39 AGREE Collaboration. Appraisal of Guidelines Research and Evaluation. AGREE, 2001 (http://www.agreecollaboration.org)

40 AGREE Collaboration. Development and validation of an international appraisal instrument for assessing the quality of clinical practice guidelines: the AGREE project. Qual Saf Health Care. 2003; 12: 18-23.

41 Landis JR, Koch GG. The measurement of observer agreement for categorical data. Biometrics 1977; 33: 159-74.

42 American Diabetes Association/American Psychiatric Association. Consensus development conference on antipsychotic drugs and obesity and diabetes. J Clin Psychiatry 2004; 65: 267-72.

43 American Diabetes Association/American Psychiatric Association. Consensus development conference on antipsychotic drugs and obesity and diabetes. Obes Res 2004; 12: 362-8.

44 Balf G, Stewar TD, Whitehead R, Baker RA. Metabolic adverse events in patients with mental illness treated with antipsychotics: a primary care perspective. Prim Care Companion J Clin Psychiatry 2008; 10: 15-24.

45 Beebe LH. Obesity in schizophrenia: screening, monitoring, and health promotion. Perspect Psychiatr Care 2008; 44: 25-31.

46 Bitter I, Jermendy G. Antipszichotikus terápia és metabolikus szindróma a Magyar Diabetes Társaság Metabolikus Munkacsoportja és a Pszichiátriai Szakmai Kollégium konszenzusértekezlete [in Hungarian]. Psychiatr Hung 2005; 20: 312-8.

47 Brooks JO, Chang H-S, Krsnykh O. Metabolic risks in older adults receiving second-generation antipsychotic medication. Curr Psychiatry Rep 2009; 11 : 33-40.

48 Covell $\mathrm{NH}$, Jackson $\mathrm{CT}$, Weissman EM. Health monitoring for patients who have schizophrenia. Summary of the Mount Sinai Conference recommendations. Postgrad Med 2006; Spec no.; 20-6.

49 De Hert M, Van Eyck D, De Nayer A. Metabolic abnormalities associated with second generation antipsychotics: fact of fiction? Development of guidelines for screening and monitoring. Int Clin Psychopharmacol 2006; 21 (suppl 2): s11-5.

50 De Hert M, Dekker JM, Wood D, Kahl KG, Holt RIG, Möller HJ. Enfermedad cardiovascular y diabetes en personas con enfermedad mental grave. Rev Psiquiatr Salud Ment 2009; 2: 49-59.

51 De Hert M, Dekker JM, Wood D, Kahl KG, Holt RIG, Möller HJ. Cardiovasculaire ziekte en diabetes bij mensen met een ernstige psychiatrische stoornis [in Dutch]. Tijdschr Geneesk 2010; 66: 269-81.

52 De Hert M, Dekker JM, Wood D, Kahl KG, Holt RIG, Möller HJ. Eine konsensuserklarung der European Psychiatric Association (EPA) zu kardiovaskularen erkrankungen und diabetes bei patienten mit einer schweren psychischen erkrankung [in Dutch]. Psychopharmakother 2010;

17: 3-13.

53 De Nayer A, De Hert M, Scheen A, Van Gaal L, Peuskens J. Troubles métaboliques associés aus antipsychotiques atypiques: consensus belge sur la conduit à tenir [in French]. Encéphale 2007; 33: 197-202.

54 Herman G, Van Eyck D, Scheen A, De Hert M. Metabole stoornissen bij patiënten met schizofrenie behandeld met tweedegeneratieantipsychotica [in Dutch]. Tijdschr Geneesk 2007; 63: 859-69.

55 Hasnain M, Vieweg WVR, Fredrickson SK, Beatty-Brooks M, Fernandez A, Pandurangi AK. Clinical monitoring and management of the metabolic syndrome in patients receiving atypical antipsychotic medications. Prim Care Diabetes 2009; 3: 5-15.
56 Jacob R, Chowdhury A. Metabolic comorbidity in schizophrenia Indian J Med Sci 2008; 62: 23-31.

57 Masand PS, Culpepper L, Henderson D, Lee S, Littrell K, Newcomer JW, et al. Metabolic and endocrine disturbances in psychiatric disorders: a multidisciplinary approach to appropriate atypical antipsychotic utilization. CNS Spectr 2005; 10: 1-15.

58 Masand PS, Culpepper L, Henderson D, Lee S, Littrell K, Newcomer JW, et al. Metabolic and endocrine disturbances in psychiatric disorders: a multidisciplinary approach to appropriate atypical antipsychotic utilization. Prim Psychiatry 2005; 12 (suppl 9): 1-16.

59 Monteleone $\mathrm{P}$, Martiadis V, Maj M. Management of schizophrenia with obesity, metabolic, and endocrinological disorders. Psychiatr Clin North Am 2009; 32: 775-94

60 Millar $\mathrm{H}$. Management of physical health in schizophrenia: a stepping stone to treatment success. Eur Neuropsychopharmacol 2008; 18: s121-8.

61 Scheen AJ, Gillian B, De Hert M. Maladie cardiovasculaire et diabète chez les personnes atteintes d'une maladie mental sévère I [in French]. Méd Maladies Métabol 2010; 4: 93-102.

62 Scheen AJ, Gillian B, De Hert M. Maladie cardiovasculaire et diabète chez les personnes atteintes d'une maladie mental sévère II [in French]. Méd Mal Métabol 2010; 4: 223-30.

63 Sernyak MJ. Implementation of monitoring and management guidelines for second-generation antipsychotics. J Clin Psychiatry 2007; 68 (suppl 4): 14-8.

64 International Psychopharmacology Algorithm Project. Metabolic Side Effects and Management. IPAP, 2004 (http://www.ipap.org/schiz).

65 Mcgorry P, Killackey E, Lambert T, Lambert M. Royal Australian and New Zealand College of Psychiatrists clinical practice guidelines for the treatment of schizophrenia and related disorders. Aust N Z J Psychiatry 2005; 39: 1-30.

66 Correll CU, Penzner JB, Parikh UH, Mughal T, Javed T, Carbon M, et al. Recognizing and monitoring adverse events of second-generation antipsychotics in children and adolescents. Child Adolesc Psychiatr Clin N Am 2006; 15: 177-206.

67 Correll CU. Monitoring and management of antipsychotic-related metabolic and endocrine adverse events in pediatric patients. Int Rev Psychiatry 2008; 20: 195-201.

68 Dobbelaere M, De Hert M. Metabole en endocriene bijwerkingen van atypische antipsychotica bij kinderen en jongeren. Richtlijnen voor de klinische praktijk [in Dutch]. Tijdschr Geneesk 2010; 66: 705-12.

69 Bobes J, Sáiz JR, Montes JM, Mostaza J, Rico-Villademoros F. Consenso Español de Salud Física del Paciente con Trastorno Bipolar [in Spanish]. Rev Psiquiatr Salud Men 2008; 1: 26-37.

70 Ng F, Mammen OK, Wilting I, Sachs GS, Ferrier IN, Cassidy F, et al. The international society for bipolar disorders (ISBD) consensus guidelines for the safety monitoring of bipolar disorder treatments. Bipolar Disord 2009; 11: 559-95.

71 Canadian Diabetes Association. Clinical practice guidelines for the prevention and management of diabetes in Canada. Can J Diabetes 2008; 32 (suppl 1): 1-215.

72 Rodbard HW, Blonde L, Braithwaite SS, Brett EM, Cobin RH, Handelsman Y, et al. American Association of Clinical Endocrinologists medical guidelines for clinical practice for the management of diabetes mellitus. Endocr Pract 2007; 13 (suppl 1): 1-68

73 Woo V, Harris, SB, Houlden RL. Canadian Diabetes Association position paper: antipsychotic medications and associates risks of weight gain and diabetes. Can J Diabetes 2005; 29: 111-2.

74 Murasaki M, Koyama T, Atsumi Y, Kadowaki T. Proposal of monitoring guidance for blood glucose in patients treated with second generation (atypical) antipsychotics. Jap J Clin Psychopharmacol 2008; 11: 1139-48.

75 American Diabetes Association/American Psychiatric Association. Consensus development conference on antipsychotic drugs and obesity and diabetes. Diabetes Care 2004; 27: 596-601.

76 Amati A, Biondi M, Bogetto F, Casacchia M, Castrogiovanni P, Giorgino F, et al. Sindrome metabolica e patologi correlate. Nella schizofrenia. Linee guida per il monitoraggio medico [in Italian]. G Ital Psicopaholt 2006; 12 (suppl 1): 5-14.

77 Barnett AH, Mackin P, Chaudhry I, Farooqi A, Gadsby R, Heald A, et al. Minimising metabolic and cardiovascular risk in schizophrenia: diabetes, obesity and dyslipidaemia. J Psychopharmachol 2007; 21: 357-73.

78 Cahn W, Ramlal D, Bruggeman R, de Haan L, Scheeepers FE, van Soest J, et al. Preventie en behandeling van somatische complicaties bij antipsychoticagebruik [in Dutch]. Tijdschr Psychiatr 2008; 50: 579-91.

79 De Hert M, Dekker JM, Wood D, Kahl KG, Holt RIG, Möller H-J. Cardiovascular disease and diabetes is people with severe mental illness position statement from the European Psychiatric Association (EPA), supported by the European 
Association for the Study of Diabetes (EASD) and the European Society of Cardiology (ESC). Eur Psychiatry 2009; 4: 412-24.

80 De Nayer A, De Hert M, Scheen A, Van Gaal L, Peuskens J. Belgian consensus on metabolic problems associated with atypical antipsychotics. Int J Psychiatr Clin Pract 2005; 9: 130-7.

81 Dinan $T$, Holt R, Kohen $\mathrm{D}$, Thakore J, Haddad $\mathrm{P}$, Baker R, et al. 'Schizophrenia and Diabetes 2003' Expert Consensus Meeting, Dublin, 3-4 October 2003: consensus summary. Br J Psychiatry 2004; 184 (suppl 47): s112-4.

82 Elkis H, Gama C, Suplicy H, Tambascia M, Bressan R, Lyra R, et al. Consenso Brasileiro sobre antipsicóticos de segunda geração e distúrbios metabólicos [in Portuguese]. Rev Bras Psiquiatr 2008; 30: 77-85.

83 Gothefors D, Adolfsson R, Attvall S, Erlinge D, Jarbin H, Lindström K, et al. Swedish clinical guidelines - prevention and management of metabolic risk in patients with severe psychiatric disorders. Nord J Psychiatry 2010; 64 294-302.

84 Lambert TJR, Chapman LH. Diabetes, psychotic disorders and antipsychotic therapy: a consensus statement. Med J Aust 2004; 181: 544-8.

85 Lefebvre N, Chereau I, Schmitt A, Llorca P-M. Comorbidités somatiques chez les patients souffrant de schizophrénie traitée. Recommandations actuelles [in French]. Ann Med Psychol 2006; 164: 159-64.

86 Marder SR, Essock SM, Miller AL, Buchanan RW, Casey DE, Davis JM, et al Physical health monitoring of patients with schizophrenia. Am J Psychiatry 2004; 161: 1334-49.

87 Melkersson $\mathrm{KI}$, Dahl M-L, Hulting A-L. Guidelines for prevention and treatment of adverse effects of antipsychotic drugs on glucose-insulin homeostasis and lipid metabolism. Psychopharmacology 2004; 175: 1-6.

88 Poulin M-J, Cortese L, Williams R, Wine N, Mcintyre RS. Atypical antipsychotics in psychiatric practice: practical implications for clinical monitoring. Can J Psychiatry 2005; 50: 555-62.

89 Saiz JR, Bobes GJ, Vallejo JR, Giner JU, Garcia-Portilla MPG. Consensus on physical health of patients with schizophrenia from the Spanish Societies of Psychiatry and Biological Psychiatry. Actas Esp Psyquiatr 2008; 36: 251-64.

90 Salokangas RKR, Hirvonen J, Honkonen T, Jyväsjärvi S, Koponen H, Laukkale T, et al. Schizophrenia treatment guideline update. Duodecim 2008; S1-22.

91 Saravane D, Feve B, Frances $Y$, Corruble E, Lancon C, Chanson $P$, et al. Élaboration de recommandations pour le suivi somatique des patients atteints de pathologie mentale sévère [in French]. Encephale 2009; 251: $1-10$.

92 Usher K, Foster K, Park T. The metabolic syndrome and schizophrenia: the latest evidence and nursing guidelines for management. J Psychiatr Ment Health Nurs 2006; 13: 730-4.

93 Henderson DC, Cagliero E, Copeland PM, Louie PM, Borba CP, Fan X, et al. Elevated hemoglobin $\mathrm{A} 1 \mathrm{C}$ as a possible indicator of diabetes mellitus and diabetic ketoacidosis in schizophrenia patients receiving atypical antipsychotics. J Clin Psychiatry 2007; 68: 533-41.

94 Hanssens L, De Hert M, Van Eyck D, Wampers M, Scheen A, Peuskens J. Usefulness of glycosylated haemoglobin (HbA1C) to screen for diabetes in patients with schizophrenia. Schizophr Res 2006; 85: 296-7.
95 The international expert committee. International Expert Committee Report on the role of the A1C assay in the diagnosis of diabetes. Diabetes Care 2009; 32: 1327-34.

96 Institute of Medicine. Guidelines for Clinical Practice: From Development to Use. National Academy Press, 1992.

97 Woolf SH, Grol R, Hutchinson A, Eccles M, Grimshaw J. Clinical guidelines: potential benefits, limitations, and harms of clinical guidelines. BMJ 1999; 318: $527-30$.

98 McAlister FA, van Diepen S, Padwal RS, Johnson JA, Majumdar SR. How evidence-based are the recommendations in evidence-based guidelines? PLOS Med 2007; 4: e250.

99 Shekelle PG, Woolf SH, Eccles M, Grimshaw J. Clinical guidelines: developing guidelines. BMJ 1999; 318: 593-6.

100 Delgado-Noguera M, Tort S, Bonfill X, Gich I, Alonso-Coello P. Quality assessment of clinical practice guidelines for the prevention and treatment of childhood overweight and obesity. Eur J Pediatr 2009; 168: 789-99.

101 Stone MA, Wilkinson JC, Charpentier G, Clochard N, Grassi G, Lindblad U, et al. Evaluation and comparison of guidelines for the management of people with type 2 diabetes from eight European countries. Diabetes Res Clin Pract 2010; 87: 252-60.

102 Graham I, Atar D, Borch-Hohnsen K, Boysen G, Burell G, Cifkova R, et al European guidelines on cardiovascular disease prevention in clinical practice: executive summary. Atherosclerosis 2007; 194: 1-45.

103 MacDermid JC, Brooks D, Solway S, Switzer-McIntyre S, Brosseau L, Graham ID. Reliability and validity of the AGREE instrument used by physical therapists in assessment of clinical practice guidelines. BMC Health Serv Res 2005; 5: 18

104 Vlayen J, Aertgeerts B, Hannes K, Sermeus W, Ramaekers D. A systematic review of appraisal tools for clinical practice guidelines: multiple similarities and one common deficit. Int J Qual Health Care 2005; 17: 235-42.

105 Pincus HA. From PORT to policy to patient outcomes: crossing the quality chasm. Schizophr Bull 2010; 36: 109-11.

106 De Hert M, Dobbelaere M, Sheridan EM, Cohen D, Correll CU. Metabolic and endocrine adverse effects of second-generation antipsychotics in children and adolescents: a systematic review of randomized, placebo controlled trials and guidelines for clinical practice. Eur Psychiatry 2011; February 3 (Epub ahead of print).

107 Alvarez-Jimenez M, Gonzalez-Blanch C, Crespo-Facorro B, Hetrick S, Rodriguez-Sanchez JM, Perez-Iglesias R, et al. Antipsychotic-induced weight gain in chronic and first-episode psychotic disorders. a systematic critical reappraisal. CNS Drugs 2008; 22: 547-62.

108 Nielsen J, Skadhede S, Correll CU. Antipsychotics associated with the development of type 2 diabetes in antipsychotic-naïve schizophrenia patients. Neuropsychopharmacology 2010; 35: 1997-2004.

109 Tarricone I, Gozzi BF, Serretti A, Grieco D, Berardi D. Weight gain in antipsychotic-naïve patients: a review and meta-analysis. Psychol Med 2010; 40: 187-200. 